\title{
Concordance of Vancomycin Population-Predicted Pharmacokinetics with Patient-Specific Pharmacokinetics in Adult Hospitalized Patients: A Case Series
}

\author{
IfeanyiChukwu O. Onor ${ }^{1,2,3}$. Alison Neuliep ${ }^{1,3} \cdot$ Kieu Anh Tran ${ }^{1}$. Jennifer Lambert ${ }^{3}$. Christopher J. Gillard ${ }^{1,2,3}$. \\ Fatima Brakta $^{2,3} \cdot$ Michael C. Ezebuenyi $^{4} \cdot$ Kirbie St. James $^{3} \cdot$ John I. Okogbaa ${ }^{1,2} \cdot$ Robbie A. Beyl $^{5}$
}

Published online: 12 March 2020

(c) The Author(s) 2020

\begin{abstract}
Background Vancomycin empiric therapy is commonly dosed using clinical algorithms adapted from population-predicted pharmacokinetic parameters. However, precise dosing of vancomycin can be designed using patient-specific pharmacokinetic calculations.

Objective The objective of this study is to assess the correlational fit between vancomycin population-predicted and patientspecific pharmacokinetic parameters [elimination rate constant $\left(K_{\mathrm{e}}\right)$ and half-life $\left(t_{1 / 2}\right)$ ] in a case series of adult hospitalized patients.

Methods This is a single-center case series of hospitalized adult patients who received vancomycin, had creatinine clearance calculation for derivation of population-predicted pharmacokinetic parameters, and had two vancomycin concentrations for calculation of patient-specific pharmacokinetic parameters. The primary objective of this case series is to evaluate the correlation between population-predicted and patient-specific pharmacokinetic parameters. The secondary objectives of this study are to evaluate the mean bias and precision between the population-predicted and patient-specific pharmacokinetic parameters and to assess the correlation between population-predicted and patient-specific pharmacokinetic parameters in special population subgroups (obese patients with body mass index $\geq 30 \mathrm{~kg} / \mathrm{m}^{2}$ and patients with renal dysfunction). All correlation analyses were performed on the population-predicted pharmacokinetics using diverse methods of estimating renal function (Salazar-Corcoran and Cockcroft-Gault methods using either ideal, actual, or adjusted body weights). All significance testing was set at an $\alpha$ of $<0.05$. IBM SPSS Statistics version 25 and SAS version 9.4 were used to conduct all statistical analyses.

Results A total of 30 patients were included in the study; 33.3\% (10/30) of the patients were obese and 56.7\% (17/30) had renal dysfunction. In all patients in the study, the calculated population-predicted $K_{\mathrm{e}}$ and $t_{1 / 2}$ using all four creatinine clearance estimation methods were each significantly correlated with patient-specific $K_{\mathrm{e}}$ and $t_{1 / 2}$ (all Pearson correlation coefficients $[r]:>+0.7, p<0.001)$. The population-predicted $K_{\mathrm{e}}$ and $t_{1 / 2}$ calculated using Cockcroft-Gault creatinine clearance using adjusted body weight showed the strongest association with patient-specific $K_{\mathrm{e}}$ and $t_{1 / 2}$. In the subgroup analyses, all the population-predicted $K_{\mathrm{e}}$ and $t_{1 / 2}$ using four creatinine clearance estimation methods were each significantly correlated with patient-specific $K_{\mathrm{e}}$ and $t_{1 / 2}$. The exception was the population-predicted $t_{1 / 2}$ derived from Cockcroft-Gault creatinine clearance using actual body weight that did not show a significant correlation with patient-specific $t_{1 / 2}$ in obese patients.

Conclusions In this case series, population-predicted pharmacokinetic parameters were strongly correlated with patientspecific pharmacokinetic parameters. The vancomycin population-predicted pharmacokinetic formula can be used safely to predict a patient's vancomycin pharmacokinetic disposition and can be maintained as an empiric dosing strategy in various hospitalized adult patients.
\end{abstract}

\section{Introduction}

Vancomycin is a glycopeptide antibiotic used in the treatment of Gram-positive aerobic and anaerobic bacteria

Extended author information available on the last page of the article such as Enterococcus, Staphylococcus, Streptococcus, and Clostridium. Since the 1950s, this antibiotic has served as the first-line therapy for methicillin-resistant Staphylococcus aureus strains and ampicillin-resistant Enterococcus species [1]. 


\section{Key Points}

This study found a strong association between patientspecific and population-based pharmacokinetic parameters that guide the initial dosing of vancomycin in most hospitals.

Our study findings show that in hospitalized patients who cannot have patient-specific pharmacokinetic parameters calculated, clinical algorithms based on population-predicted pharmacokinetic parameters can be used for vancomycin dosing.

Vancomycin empiric dose selection is weight based and the selection of dosing frequency is often adapted from population-predicted pharmacokinetic parameter estimates and/ or using patient-specific pharmacokinetic parameters when two vancomycin concentrations are obtained [1, 2]. Matzke et al. have proposed the most common population-predicted pharmacokinetic elimination rate constant $\left(K_{\mathrm{e}}\right)$ used in the calculation of half-life $\left(t_{1 / 2}\right)$ and clearance for vancomycin elimination [2]. This equation $\left(K_{\mathrm{e}}=[0.00083 \times\right.$ creatinine clearance $(\mathrm{CrCl})]+0.0044)$ is used routinely in many hospitals to develop clinical algorithms for selecting initial vancomycin dose frequency [2]. Alternatively, after two vancomycin concentrations are obtained, the patient-specific pharmacokinetic $K_{\mathrm{e}}$ can be calculated using a patient's vancomycin concentrations and can inform more precise selection of vancomycin dose frequency.

In a recent study, using the Matzke population-predicted $K_{\mathrm{e}}$ formula $=0.00083 \times \mathrm{CrCl}+0.0044$ [2], Oswalt et al. found that population and patient-specific $K_{\mathrm{e}}$ and half-life were similar in 158 patients with acute brain injury. More specifically, the study found statistically significant differences between the mean population-predicted and patient-specific $K_{\mathrm{e}}$ and $t_{1 / 2}$; however, these were negligible clinical differences with a mean $K_{\mathrm{e}}$ difference of $0.0211 \mathrm{~h}^{-1}$ and a mean $t_{1 / 2}$ difference of $1.01 \mathrm{~h}$ [3]. The study authors concluded that populationpredicted pharmacokinetics may be an accurate empiric dosing strategy for selecting vancomycin dose frequency given the small clinical difference between population-predicted and patient-specific $K_{\mathrm{e}}$. Additionally, Murphy and colleagues evaluated seven methods for estimating vancomycin pharmacokinetic parameters ( $K_{\mathrm{e}}$, volume of distribution, and vancomycin clearance) and concluded that these methods varied widely in their ability to predict vancomycin concentrations with measured vancomycin concentrations. The authors noted that the seven methods were not reliable to replace therapeutic monitoring of vancomycin concentrations [4]. However, the authors found that out of all the seven methods for estimating vancomycin pharmacokinetic parameters, the Matzke method had the least bias and best precision compared with the other six methods assessed [2, 4].

Previous studies have shown that factors such as age, renal function, and body weight influence vancomycin clearance and modulate vancomycin pharmacokinetics [5-9]. Various studies have looked at several equations used in estimating $\mathrm{CrCl}$ in obese patients with evolving divergent findings on the best equations and body weight to use [10-15]. The Salazar-Corcoran (S-C) equation had been proposed as the best method for estimating $\mathrm{CrCl}$ in obese patients with a body mass index $\geq 30 \mathrm{~kg} / \mathrm{m}^{2}$ and this finding was corroborated by the study by Spinler et al. [10, 11]. However, more recent studies have been testing the use of the Cockcroft-Gault $(\mathrm{C}-\mathrm{G})$ equation to estimate $\mathrm{CrCl}$ [12] using ideal body weight, actual body weight, lean body weight, and $40 \%$ adjusted body weight [adjusted body weight $=$ ideal body weight $+0.4 \times$ (actual body weight - ideal body weight)] [13-15]. Initially, using lean body weight in the $\mathrm{C}-\mathrm{G}$ equation was promising [14]; however, using the $40 \%$ adjusted body weight in the $\mathrm{C}-\mathrm{G}$ equation has emerged as the least biased and most accurate method for calculating the $\mathrm{C}-\mathrm{G} \mathrm{CrCl}[15]$.

The primary objective of this case series is to evaluate the correlation between patient-specific vs population-predicted vancomycin pharmacokinetic parameters $\left(K_{\mathrm{e}}\right.$ and $\left.t_{1 / 2}\right)$ in a case series of hospitalized patients at an academic medical center. We aim for findings from this study to contribute to the literature and influence clinicians' confidence on the use of population-predicted vancomycin pharmacokinetics $K_{\mathrm{e}}$ and $t_{1 / 2}$ when obtaining patient-specific $K_{\mathrm{e}}$ and $t_{1 / 2}$ is impractical or impossible.

\section{Methods}

\subsection{Study Design and Patient Population}

This is a single-center case series of patients who received vancomycin pharmacokinetic monitoring at University Medical Center, New Orleans, Louisiana from 1 July, 2018 to 30 May, 2019. This study was approved by the Institutional Review Board of Xavier University of Louisiana and the University Medical Center Research Review Committee. The target sample size proposed for this case series is approximately 20-40 patients based on a priori estimates on the number of patients who will meet inclusion criteria over the specified study timeframe.

All patients who were 18 years of age and older and received vancomycin therapy were included in the study. Patients were included if they were on the vancomycin monitoring list serviced by the primary investigator, had serum creatinine for calculation of population-predicted pharmacokinetic parameters, and had two vancomycin 
concentrations for calculation of patient-specific pharmacokinetic parameters. Patients were included if their vancomycin concentrations and serum creatinine were obtained within a 1-day period. Patients were excluded if vancomycin doses were given in between the two vancomycin concentrations.

\subsection{Data Collection}

The following demographic and clinical variables were collected on patients: age, sex, race, height, actual body weight (ABW), ideal body weight (IBW), adjusted body weight (AdjBW), body mass index, serum creatinine, $\mathrm{C}-\mathrm{G} \mathrm{CrCl}$ using IBW (C-G CrCl-IBW), $\mathrm{C}-\mathrm{G} \mathrm{CrCl}$ using $\mathrm{ABW}$ (C-G $\mathrm{CrCl}-\mathrm{ABW}$ ), $\mathrm{C}-\mathrm{G} \mathrm{CrCl}$ using AdjBW (C-G CrCl-AdjBW), $\mathrm{S}-\mathrm{C} \mathrm{CrCl}$ using $\mathrm{ABW}$ (S-C CrCl-ABW), first serum vancomycin concentration during elimination phase, second serum vancomycin concentration during elimination phase, hours apart between vancomycin concentrations for patient-specific pharmacokinetics, and time from last vancomycin dose to first serum vancomycin concentration during elimination phase. In addition, the following predictor variables were collected: $K_{\mathrm{e}}$ using C-G CrCl-IBW, $K_{\mathrm{e}}$ using C-G CrCl-ABW, $K_{\mathrm{e}}$ using $\mathrm{C}-\mathrm{G} \mathrm{CrCl}-\mathrm{AdjBW}, K_{\mathrm{e}}$ using $\mathrm{S}-\mathrm{C} \mathrm{CrCl} \mathrm{ABW}, t_{1 / 2}$ using $\mathrm{C}-\mathrm{G}$ CrCl-IBW, $t_{1 / 2}$ using $\mathrm{C}-\mathrm{G} \mathrm{CrCl}-\mathrm{ABW}, t_{1 / 2}$ using $\mathrm{C}-\mathrm{G} \mathrm{CrCl}-$ AdjBW, and $t_{1 / 2}$ using S-C CrCl-ABW. Collected outcome variables were patient-specific $K_{\mathrm{e}}$ and patient-specific $t_{1 / 2}$. All diagnoses were supported with a documented physician diagnosis and confirmed on the electronic medical record using the definition criteria below. Acute kidney injury was defined, based on the Kidney Disease: Improving Global Outcomes guideline, as an increase in serum creatinine by $\geq 0.3 \mathrm{mg} / \mathrm{dL}$ within $48 \mathrm{~h}$; or an increase in serum creatinine to $\geq 1.5$ times the baseline, which is known or presumed to have occurred within the prior 7 days; or urine volume $<0.5 \mathrm{~mL} / \mathrm{kg} / \mathrm{h}$ for $6 \mathrm{~h}$ [16]. Chronic kidney disease was defined, based on the Kidney Disease: Improving Global Outcomes guideline, as the presence of either kidney damage or decreased kidney function for 3 or more months, irrespective of cause [17]. The chronic kidney disease definition accounted for: durationduration $\geq 3$ months, predicted on documentation or inference; function - glomerular filtration rate $<60 \mathrm{~mL} / \mathrm{min} / 1.73 \mathrm{~m}^{2}$ (glomerular filtration rate categories G3a-G5); and damagekidney damage, as defined by structural abnormalities or functional abnormalities other than decreased glomerular filtration rate such as albuminuria (albumin excretion rate $\geq 30 \mathrm{mg} / 24 \mathrm{~h}$; albumin-to-creatinine ratio $\geq 30 \mathrm{mg} / \mathrm{g}$ [ $\geq 3 \mathrm{mg} / \mathrm{mmol}]$ ), urine sediment abnormalities, electrolyte and other abnormalities due to tubular disorders, abnormalities detected by histology, structural abnormalities detected by imaging, and history of kidney transplantation. End-stage renal disease was defined as chronic kidney failure in which a person's kidneys cease functioning on a permanent basis leading to the need for a regular course of long-term dialysis or a kidney transplant to maintain life. [18].

Weight was calculated using one of the following equations:

Actual body weight (ABW) for male and female patients

$=$ Measured weight using weighing scale

Ideal body weight (IBW)for male patients

$=50+2.3$ (height in inches $>60$ inches)

Ideal body weight (IBW) for female patients $=45.5+2.3$ (height in inches $>60$ inches)

Adjusted body weight for male patients

$=I \mathrm{BW}$ for male patients +0.4 (ABW - IBW for male patients $)$

Adjusted body weight for female patients

$=\mathrm{IBW}$ for female patients $+0.4(\mathrm{ABW}-\mathrm{IBW}$ for female patients $)$

where weight is in kilograms, and height is in inches.

Creatinine clearance was calculated using one of the following equations:

Cockcroft-Gault $(C-G)$ equation for male patients

$$
=\frac{(140-\text { age })(\text { weight })}{(72)(\text { serum creatinine })}
$$

Cockcroft-Gault (C-G)equation for female patients

$$
=\frac{(140-\text { age })(\text { weight })}{(72)(\text { serum creatinine })} \times 0.85
$$

Salazar-Corcoran $(\mathrm{S}-\mathrm{C})$ equation for male patients

$$
=\frac{(137-\text { Age })(0.285 \times \text { weight })+\left(12.1 \times \text { height }^{2}\right)}{(51)(\text { serum creatinine })}
$$

Salazar-Corcoran $(\mathrm{S}-C)$ equation for female patients

$$
=\frac{(146-\text { Age })(0.287 \times \text { weight })+\left(9.74 \times \text { height }^{2}\right)}{(60)(\text { serum creatinine })}
$$

where age is in years, weight is in kilograms, height is in meters, and serum creatinine is in milligram $(\mathrm{mg}) /$ deciliter (dL). Weight is either actual body weight (ABW), ideal body weight (IBW), or adjusted body weight (AdjBW) for the $\mathrm{C}-\mathrm{G}$ equation and weight is actual body weight (ABW) for the $\mathrm{S}-\mathrm{C}$ equation.

Population-predicted pharmacokinetic parameters were calculated using the following equations [2]:

$K_{\mathrm{e}}=(0.00083 \times C r C l)+0.0044$ 
$t_{1 / 2}=\frac{0.693}{K_{\mathrm{e}}}$,

where $K_{\mathrm{e}}$ is the first-order elimination rate constant, $\mathrm{CrCl}$ is the creatinine clearance in $\mathrm{mL} / \mathrm{min}$ based on the $\mathrm{C}-\mathrm{G}$ equation or $\mathrm{S}-\mathrm{C}$ equation, and $t_{1 / 2}$ is the half-life.

Patient-specific pharmacokinetic parameters were calculated using the following equations [19]:

$K_{\mathrm{e}}=\frac{\ln \left(\frac{C 1}{C 2}\right)}{\text { time hours between } C 1 \text { and } C 2}$

$t_{1 / 2}=\frac{0.693}{K_{\mathrm{e}}}$,

where $K_{e}$ is the first-order elimination rate constant, $C 1$ is the first vancomycin concentration drawn at least $2 \mathrm{~h}$ after vancomycin is fully administered to ensure vancomycin post-administration distribution phase is complete [20], $C 2$ is the second vancomycin concentration drawn after $C 1$, and $t_{1 / 2}$ is the half-life. Vancomycin doses were not given in between $C 1$ and $C 2$.

The default vancomycin infusion durations were $1 \mathrm{~h}$ for vancomycin $\leq 1000 \mathrm{mg}, 1.5 \mathrm{~h}$ for vancomycin $1250-1500 \mathrm{mg}, 2 \mathrm{~h}$ for vancomycin $1750-2000 \mathrm{mg}$, and $3 \mathrm{~h}$ for vancomycin $2250-3000 \mathrm{mg}$. Data on whether vancomycin concentration was collected at steady state were assessed. Steady-state concentration was defined as a vancomycin concentration obtained prior to the fourth maintenance dose for patients with normal renal function and prior to the third dose for patients with renal dysfunction (acute kidney injury, chronic kidney disease, and end-stage renal disease); consistent with our hospital protocol [21].

\subsection{Study Objectives}

The primary objective of this study is to evaluate the correlation between population-predicted and patient-specific pharmacokinetic parameters $\left(K_{\mathrm{e}}\right.$ and $\left.t_{1 / 2}\right)$. The secondary objectives of this study is to evaluate the mean bias and precision between the population-predicted and patientspecific pharmacokinetic parameters $\left(K_{\mathrm{e}}\right.$ and $\left.t_{1 / 2}\right)$ in select adult medicine patients. A subgroup analysis was performed to assess the correlation between population-predicted and patient-specific pharmacokinetic parameters $\left(K_{\mathrm{e}}\right.$ and $\left.t_{1 / 2}\right)$ in special populations-obese patients with a body mass index $\geq 30 \mathrm{~kg} / \mathrm{m}^{2}$ and patients with renal dysfunction (acute kidney injury, chronic kidney disease, and end-stage renal disease). All correlation analyses were performed on the population-predicted pharmacokinetics using diverse methods of estimating renal function ( $\mathrm{S}-\mathrm{C}$ and $\mathrm{C}-\mathrm{G}$ methods using either ideal, actual, and adjusted body weights).

\subsection{Statistical Analyses}

Descriptive statistics were used to describe the study demographic characteristics. Simple linear regression analysis was performed to assess the Pearson correlation coefficient $(r)$ and the unstandardized coefficient $(\beta) \pm$ standard error between population-predicted and patient-specific pharmacokinetic parameters: $K_{\mathrm{e}}$ and $t_{1 / 2}$. The Student's $t$ test was used to compare mean differences between the populationpredicted and patient-specific pharmacokinetic parameters $\left(K_{\mathrm{e}}\right.$ and $\left.t_{1 / 2}\right)$ in patients. An F-test is used to test if the ratio of the two precision estimates between the two groups is different. All significance testing was set at an $\alpha$ of $<0.05$. IBM SPSS Statistics version 25 and SAS version 9.4 were used to conduct all statistical analyses.

\section{Results}

A total of 30 patients were included in the study. $33.3 \%$ (10/30) of the patients were obese and $56.7 \%$ (17/30) of the patients had renal dysfunction (11 had acute kidney injury, 1 had chronic kidney disease, 3 had both acute kidney injury and chronic kidney disease, and 2 had end-stage renal disease). Of the 30 patients, 23 patients (76.7\%) were at steady state when the vancomycin concentration was drawn, six patients did not reach steady state when the vancomycin concentration was drawn, and for 1 patient, we could not decide whether the patients was at steady state because the patient received the vancomycin dose at an outside hospital and had no documented record of the vancomycin doses received at the outside hospital. Out of the 23 patients who were at steady state, only four were counted as reaching steady state prior to the third dose as the patients had renal dysfunction. Seven patients were hospitalized in the intensive care unit and 23 patients were admitted in non-intensive care unit inpatient settings when the vancomycin concentration was drawn. Tables 1, 2, and 3 provide information on our hospital's vancomycin protocol and patients' baseline information.

Tables 4 and 5 show the relationship between the population-predicted pharmacokinetic parameters $\left(K_{\mathrm{e}}\right.$ and $\left.t_{1 / 2}\right)$ and patient-specific pharmacokinetic parameters $\left(K_{\mathrm{e}}\right.$ and $\left.t_{1 / 2}\right)$ in all patients. All the calculated population-predicted $\mathrm{K}_{\mathrm{e}}$ and $\mathrm{t}_{1 / 2}$ using all four $\mathrm{CrCl}$ estimation methods were each significantly correlated with patient specific $\mathrm{K}_{\mathrm{e}}$ and $\mathrm{t}_{1 / 2}$; with the population-predicted $K_{\mathrm{e}}$ and $t_{1 / 2}$ calculated using $\mathrm{C}-\mathrm{G} \mathrm{CrCl}$-AdjBW showing the strongest association with patient-specific $K_{\mathrm{e}}$ and $t_{1 / 2}$. Figures 1,2, 3 and 4 provide a 
simple linear regression graph of the relationship between the patient-specific $K_{\mathrm{e}}$ and population-predicted $K_{\mathrm{e}}$ calculated using different methods for estimating $\mathrm{CrCl}$.

When evaluating the mean difference in bias between the population-predicted parameter; $K_{\mathrm{e}}$ (Table 6), there was no significant mean difference between the patient-specific $\mathrm{K}_{\mathrm{e}}$ and population-predicted $K_{\mathrm{e}}$ calculated using $\mathrm{C}-\mathrm{G} \mathrm{CrCl}$ IBW and C-G CrCl-AdjBW. The mean patient-specific $K_{\mathrm{e}}$ was significantly different from the population-predicted $K_{\mathrm{e}}$ calculated using $\mathrm{C}-\mathrm{G} \mathrm{CrCl}-\mathrm{ABW}$ and $\mathrm{S}-\mathrm{C} \mathrm{CrCl}-\mathrm{ABW}$; however, the mean differences observed were small at $0.018 \mathrm{~h}^{-1}$ and $0.016 \mathrm{~h}^{-1}$, respectively. There were no significant differences in precision between any of the population-predicted $K_{\mathrm{e}}$ and the patient-specific $K_{\mathrm{e}}$. Table 7 shows the $\mathrm{t}_{1 / 2}$ calculation derived from the $K_{\mathrm{e}}$ from Table 6 . All population-predicted $t_{1 / 2}$ were significantly different from patient-specific $t_{1 / 2}$. Likewise, the precision of all the population-predicted $\mathrm{t}_{1 / 2}$ were smaller than the patient-specific $K_{\mathrm{e}}$.

Tables 8 and 9 show the relationship between the population-predicted $K_{\mathrm{e}}$ and $t_{1 / 2}$ and patient-specific $K_{\mathrm{e}}$ and $t_{1 / 2}$ in obese patients. All the population-predicted $K_{\mathrm{e}}$ using different $\mathrm{CrCl}$ methods were significantly correlated with patientspecific $K_{\mathrm{e}}$. The population-predicted $\mathrm{t}_{1 / 2}$ was significantly correlated with patient-specific $\mathrm{t}_{1 / 2}$ using three different $\mathrm{CrCl}$ methods with the population-predicted $t_{1 / 2}$ derived from $\mathrm{C}-\mathrm{G}$
CrCl-ABW not showing a strong correlation with patientspecific $t_{1 / 2}$. The population-predicted $K_{\mathrm{e}}$ and $t_{1 / 2}$ calculated using $\mathrm{C}-\mathrm{G} \mathrm{CrCl}-\mathrm{IBW}$ showed the strongest association with patient-specific $K_{\mathrm{e}}$ and $t_{1 / 2}$ in obese patients. Among patients with renal dysfunction (Tables 10 and 11), all the population-predicted $K_{\mathrm{e}}$ and $t_{1 / 2}$ were significantly correlated with patient-specific $K_{\mathrm{e}}$ and $t_{1 / 2}$. The population-predicted $K_{\mathrm{e}}$ using C-G CrCl-ABW had the strongest correlation to the patient-specific $K_{\mathrm{e}}$, while the population-predicted $t_{1 / 2}$ using $\mathrm{C}-\mathrm{G} \mathrm{CrCl}$-AdjBW had the strongest correlation to the patient-specific $\mathrm{t}_{1 / 2}$ in patients with renal dysfunction.

\section{Discussion}

To our knowledge, this is the first study examining the correlation between vancomycin population-predicted and patient-specific pharmacokinetic parameters. This study noted that regardless of the $\mathrm{CrCl}$ method used, the Matzke population-predicted $K_{\mathrm{e}}$ was reliable and strongly correlated to the patient-specific $K_{\mathrm{e}}$. Our study findings were consistent with findings from the Oswalt et al. and Murphy et al. studies $[3,4]$. The Oswalt study found small, clinically negligible differences between the population-predicted and patient-specific pharmacokinetics and concluded that using

Table 1 Vancomycin dosing guide protocol used at the University Medical Center, New Orleans [21]

University Medical Center New Orleans protocol for goal vancomycin trough of $15-20 \mathrm{mcg} / \mathrm{mL}$ Serious infections: bacteremia, endocarditis, osteomyelitis, meningitis, and pneumonia

\begin{tabular}{ll}
\hline Actual body weight $(\mathrm{kg})$ & Vancomycin dose range (mg) \\
$50-64$ & $750-1000$ \\
$65-94$ & $1000-1250$ \\
$\geq 95$ & 1500 \\
$\mathrm{CrCl}(\mathrm{mL} / \mathrm{min})$ & Dosing interval (h) \\
$30-49$ & 24 \\
$50-79$ & $12-24$ \\
$\geq 80$ & $8-12$ \\
\hline University Medical Center New Orleans protocol for goal vancomycin trough of 10-15 mcg/mL & \\
Mild infections: urinary tract and skin and soft-tissue infections & Vancomycin dose range (mg) \\
\hline Actual body weight (kg) & $500-1000$ \\
$50-64$ & $750-1000$ \\
$65-94$ & $1000-1250$ \\
$\geq 95$ & Dosing interval (h) \\
CrCl (mL/min) & 24 \\
$30-49$ & $12-24$ \\
$50-79$ & $8-12$
\end{tabular}

$\mathrm{CrCl}$ creatinine clearance 
Table 2 Baseline characteristics

Baseline characteristics $(N=30)$

Mean age (years) \pm SD [range]

$48.9 \pm 14.01[26-76]$

Sex, $n(\%)$

Male: 20 (66.7)

Race, $n(\%)$

Female: $10(33.3)$

Whites: 12 (40)

Black/African-

Americans: 14

(46.7)

Others: 4 (13.3)

Mean height $(\mathrm{cm}) \pm \mathrm{SD}$

$172.51 \pm 11.04$

Mean actual body weight $(\mathrm{kg}) \pm \mathrm{SD}$

$85.85 \pm 24.93$

Mean ideal body weight $(\mathrm{kg}) \pm \mathrm{SD}$

$66.82 \pm 11.60$

Mean body mass index $\left(\mathrm{kg} / \mathrm{m}^{2}\right) \pm \mathrm{SD}$

$28.70 \pm 7.32$

Mean body mass index in obese patients $\left(\mathrm{kg} / \mathrm{m}^{2}\right) \pm \mathrm{SD}[n=10]$

$37.23 \pm 5.82$

Mean serum creatinine $(\mathrm{mg} / \mathrm{dL}) \pm \mathrm{SD}$

$2.29 \pm 2.06$

Median serum creatinine $(\mathrm{mg} / \mathrm{dL})$ [range]

$1.47[0.57-8.69]$

Mean serum creatinine $(\mathrm{mg} / \mathrm{dL})$ in patients with renal dysfunction $\pm \operatorname{SD}[n=17]$

$3.38 \pm 2.18$

Mean initial vancomycin dose $(\mathrm{mg}) \pm \mathrm{SD}$

$1258.3 \pm 350.39$

Mean initial vancomycin dose per weight $(\mathrm{mg} / \mathrm{kg}) \pm \mathrm{SD}$

$15.1 \pm 4.01$

Mean current vancomycin dose at the day vancomycin concentration was drawn $(\mathrm{mg}) \pm \mathrm{SD}$

$1225 \pm 355.68$

Mean current vancomycin dose per weight at the day vancomycin concentration was drawn $(\mathrm{mg} / \mathrm{kg}) \pm \mathrm{SD}$

$14.5 \pm 3.30$

Mean initial vancomycin dosing interval $(\mathrm{h}) \pm \mathrm{SD}(N=25)$

$14.1 \pm 5.90$

Median initial vancomycin dosing interval (h) [range] $(N=25)$

12 [8-24]

Mean current vancomycin dosing interval at the day vancomycin concentration was drawn $(\mathrm{h}) \pm \mathrm{SD}(N=25)$

$14.8 \pm 6.83$

Median current vancomycin dosing interval at the day vancomycin concentration was drawn (h) [range] $(N=25)$

12 [8-24]

Mean time from vancomycin administration to $\mathrm{C} 1$ levels $(\mathrm{h}) \pm \mathrm{SD}$

$13.10 \pm 6.54$

Mean time between $\mathrm{C} 1$ and $\mathrm{C} 2$ levels $(\mathrm{h}) \pm \mathrm{SD}$

$13.11 \pm 7.31$

Percent of patient with steady-state vancomycin concentration ordered, $n(\%)$

$23(76.7)$

$S D$ standard deviation

Table 3 Infections treated in all patients

\begin{tabular}{llc}
\hline Infections $(N=30)$ & & \\
\hline Methicillin-resistant infections, $n(\%)$ & Methicillin-resistant Staphylococcus aureus & $14(46.7)$ \\
& Methicillin-resistant Staphylococcus epidermidis & $1(3.3)$ \\
& Non-methicillin-resistant infections & $15(50)$ \\
Organ system infections, $n(\%)$ & Osteomyelitis & $8(26.7)$ \\
& Surgical-site infections & $2(6.7)$ \\
& Central nervous system & $2(6.7)$ \\
& Endocarditis ${ }^{\text {a }}$ & $4(13.3)$ \\
& Bacteremia only & $4(13.3)$ \\
& Skin and soft-tissue infections & $5(16.7)$ \\
& Sepsis & $3(10)$ \\
& Pneumonia & $1(3.3)$ \\
& Spontaneous bacterial peritonitis & $1(3.3)$ \\
Definitive vs. empiric infections & Definitive (organism isolated) & $16(53.3)$ \\
& Empiric (no organism isolated) & $14(46.7)$ \\
\hline
\end{tabular}

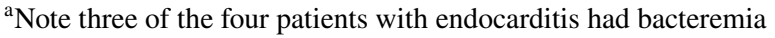


Table 4 Relationship between population-predicted elimination rate constant $\left(K_{\mathrm{e}}\right)$ and patient-specific $K_{\mathrm{e}}$ in all patients $(n=30)$

\begin{tabular}{llll}
\hline & \multicolumn{3}{l}{$\begin{array}{l}\text { Patient-specific } \mathrm{K}_{\mathrm{e}} \text { outcome } \\
\text { variable }\end{array}$} \\
\cline { 2 - 5 } Predictor variables & $r$ & $\beta \pm \mathrm{SE}$ & $P$ value \\
\hline$K_{\mathrm{e}}$ using C-G CrCl-IBW $\left(\mathrm{h}^{-1}\right)$ & 0.718 & $0.916 \pm 0.168$ & $<0.001$ \\
$K_{\mathrm{e}}$ using C-G CrCl-ABW $\left(\mathrm{h}^{-1}\right)$ & 0.711 & $0.732 \pm 0.137$ & $<0.001$ \\
$K_{\mathrm{e}}$ using C-G CrCl-AdjBW $\left(\mathrm{h}^{-1}\right)$ & 0.729 & $0.867 \pm 0.154$ & $<0.001$ \\
$K_{\mathrm{e}}$ using S-C CrCl-ABW $\left(\mathrm{h}^{-1}\right)$ & 0.725 & $0.784 \pm 0.141$ & $<0.001$ \\
\hline
\end{tabular}

$A B W$ actual body weight, $A d j B W$ adjusted body weight, $C G$ Cockcroft-Gault, $\mathrm{CrCl}$ creatinine clearance, $I B W$ ideal body weight, $S-C$ Salazar-Corcoran, $S E$ standard error

Table 5 Relationship between population-predicted half-life $\left(t_{1 / 2}\right)$ and patient-specific $t_{1 / 2}$ in all patients $(n=30)$

\begin{tabular}{llll}
\hline & \multicolumn{3}{l}{$\begin{array}{l}\text { Patient-specific } \mathrm{t}_{1 / 2} \text { outcome vari- } \\
\text { able }\end{array}$} \\
\cline { 2 - 5 } Predictor variables & $r$ & $\beta \pm \mathrm{SE}$ & $P$ value \\
\hline$t_{1 / 2}$ using C-G CrCl-IBW (h) & 0.767 & $1.255 \pm 0.198$ & $<0.001$ \\
$t_{1 / 2}$ using C-G CrCl-ABW (h) & 0.752 & $1.293 \pm 0.214$ & $<0.001$ \\
$t_{1 / 2}$ using C-G CrCl-AdjBW (h) & 0.773 & $1.315 \pm 0.204$ & $<0.001$ \\
$t_{1 / 2}$ using S-C CrCl-ABW (h) & 0.761 & $1.419 \pm 0.228$ & $<0.001$ \\
\hline
\end{tabular}

$A B W$ actual body weight, $A d j B W$ adjusted body weight, $C G$ Cockcroft-Gault, $\mathrm{CrCl}$ creatinine clearance, $\mathrm{IBW}$ ideal body weight, $\mathrm{S}-\mathrm{C}$ Salazar-Corcoran, SE standard error

population-predicted pharmacokinetics may be an accurate empiric dosing strategy for determining vancomycin dosing frequency in patients with acute brain injury. ${ }^{3}$ Similar to the Oswalt et al. study, our study found two small and clinically negligible significant differences between patientspecific and population-predicted pharmacokinetics using $\mathrm{C}-\mathrm{G} \mathrm{CrCl}-\mathrm{ABW}$ and $\mathrm{S}-\mathrm{C} \mathrm{CrCl}-\mathrm{ABW}$, while there was no significant bias between patient-specific and two populationpredicted pharmacokinetics using $\mathrm{C}-\mathrm{G}$ CrCl-IBW and $\mathrm{C}-\mathrm{G}$ $\mathrm{CrCl}$-AdjBW. The Murphy et al. study also noted that the Matzke population-predicted pharmacokinetic parameter (which was used in our study) performed best compared with the other six methods evaluated in their study.

In our study, we observed that regardless of the $\mathrm{CrCl}$ estimation method used, the population-predicted $K_{\mathrm{e}}$ was significantly correlated with patient-specific $K_{\mathrm{e}}$. However, population-predicted $K_{\mathrm{e}}$ using C-G CrCl-AdjBW had the strongest correlation with patient-specific $K_{\mathrm{e}}$ in all patients in our case series. In the subgroup analyses of special populations, population-predicted $K_{\mathrm{e}}$ using C-G CrCl-IBW had the strongest correlation with patient-specific $K_{\mathrm{e}}$ in obese patients and the population-predicted $K_{\mathrm{e}}$ using C-G CrCl$\mathrm{ABW}$ had the strongest correlation in patients with renal dysfunction. This slightly stronger favoring of the $\mathrm{C}-\mathrm{G}$ $\mathrm{CrCl}$-IBW as the best method for calculating populationpredicted $\mathrm{K}_{\mathrm{e}}$ is somewhat inconsistent with other studies, which have previously reported that the $\mathrm{C}-\mathrm{G} \mathrm{CrCl}-\mathrm{IBW}$ underestimates $\mathrm{CrCl}$ in obese patients [14, 22]. This finding of the better performance of the $\mathrm{C}-\mathrm{G} \mathrm{CrCl}$-IBW for the calculation of population-predicted $K_{\mathrm{e}}$ in obese patients should be interpreted cautiously given the limitations of our small study. The $\mathrm{S}-\mathrm{C}$ equation was also not the best method in obese patients as supported by prior studies $[10,11]$. The population-predicted $K_{\mathrm{e}}$ using $\mathrm{C}-\mathrm{G} \mathrm{CrCl}$-ABW had the best correlation to patient-specific $K_{\mathrm{e}}$ in patients with renal dysfunction. The assessment of the correlation between patient-specific and population-predicted pharmacokinetics in patients with renal dysfunction was an exploratory subgroup analysis in our case series. It is worth noting that two methods, not used in our case series, have been previously proposed for calculating $\mathrm{CrCl}$ in patients with renal dysfunction, although these methods are dated and need validation in a larger population [23, 24].

Our study has some strengths and limitations. The strength of this study is that it evaluated a mix of adult patients that is
Fig. 1 Relationship between population-predicted elimination rate constant $\left(K_{\mathrm{e}}\right)$ using Cockcroft-Gault creatinine clearance-ideal body weight (C-G CrCl-IBW) and patientspecific $K_{\mathrm{e}}(r=0.718$; coefficient of determination $\left[R^{2}\right]=0.516 ; n=30$ )

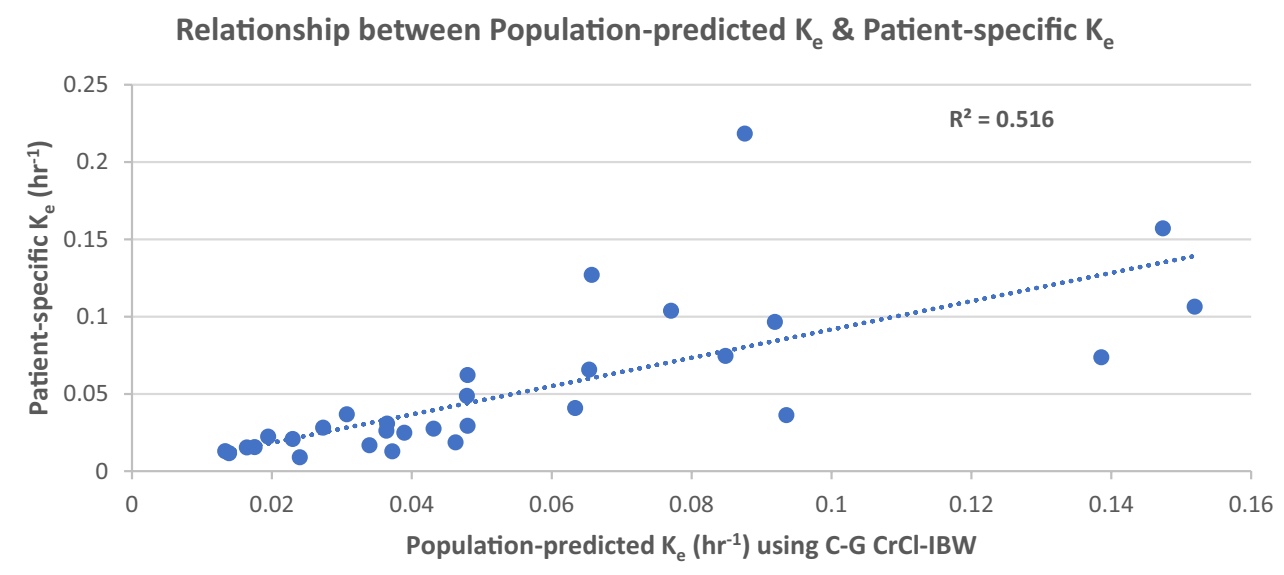


Fig. 2 Relationship between population-predicted elimination rate constant $\left(K_{\mathrm{e}}\right)$ using Cockcroft-Gault creatinine clearance-actual body weight (C-G CrCl-ABW) and patient-specific $K_{\mathrm{e}}(r=0.711$; $R^{2}=0.505 ; n=30$ )
Fig. 3 Relationship between population-predicted elimination rate constant $\left(K_{\mathrm{e}}\right)$ using Cockcroft-Gault creatinine clearance-adjusted body weight (C-G CrCl-AdjBW) and patient-specific $K_{\mathrm{e}}(r=0.729$; $R^{2}=0.532 ; n=30$ )
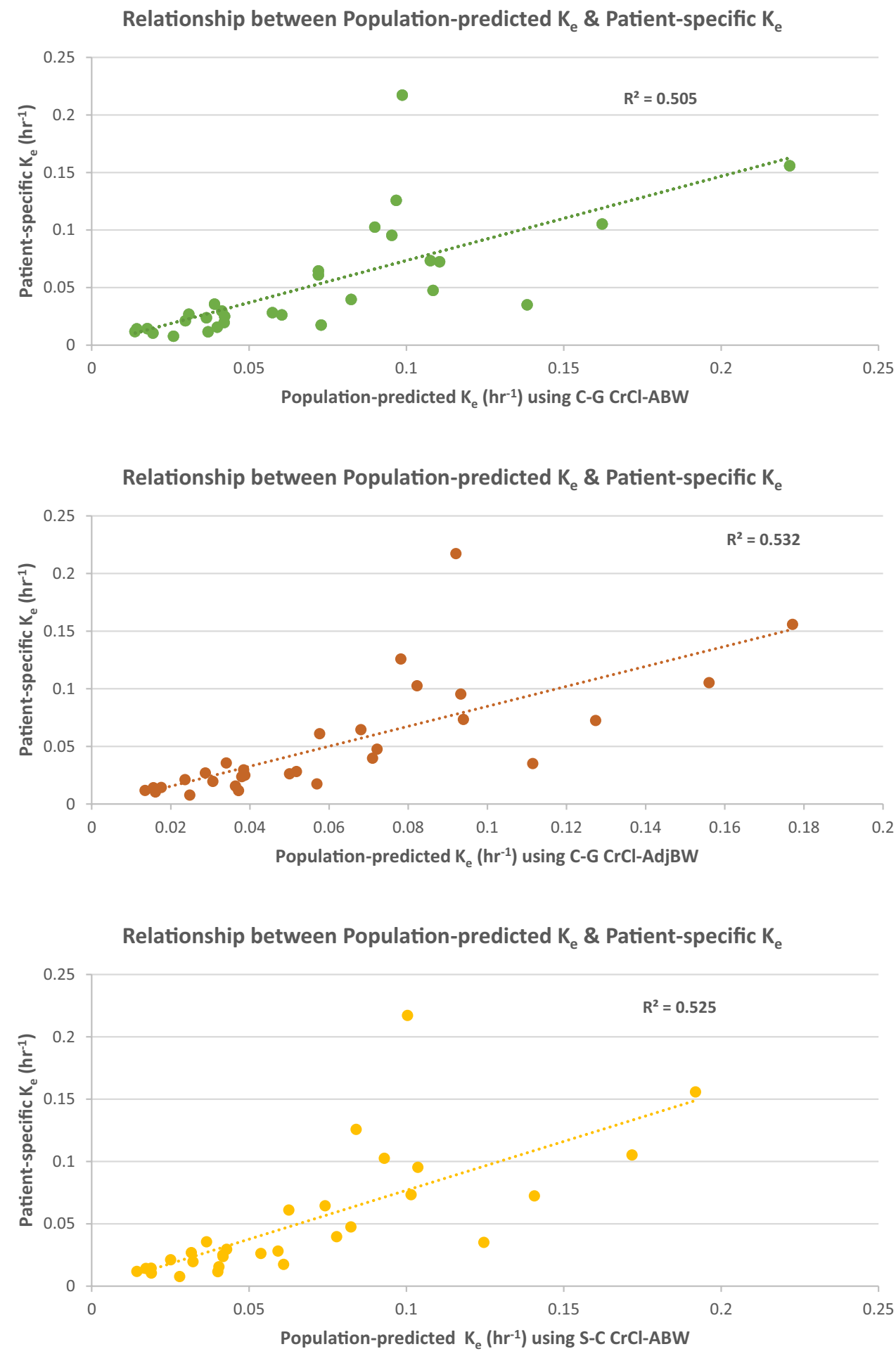

Relationship between Population-predicted $\mathrm{K}_{\mathrm{e}}$ \& Patient-specific $\mathrm{K}_{\mathrm{e}}$

Population-predicted $\mathrm{K}_{\mathrm{e}}\left(\mathrm{hr}^{-1}\right)$ using C-G CrCl-ABW
Fig. 4 Relationship between population-predicted elimination rate constant $\left(K_{\mathrm{e}}\right)$ using Salazar-Corcoran creatinine clearance-actual body weight ( $\mathrm{S}-\mathrm{C} \mathrm{CrCl}-\mathrm{ABW}$ ) and patient-specific $K_{\mathrm{e}}(r=0.725$; $R^{2}=0.525 ; n=30$ ) . 
Table 6 Mean bias and precision between populationpredicted elimination rate constant $\left(K_{\mathrm{e}}\right)$ and patientspecific $K_{\mathrm{e}}$ in all patients $(n=30)$

\begin{tabular}{llllll}
\hline Outcome & Predictor variables & $\begin{array}{l}\text { Population- } \\
\text { predicted } K_{\mathrm{e}}\end{array}$ & $\begin{array}{l}\text { Patient-specific } K_{\mathrm{e}} \\
\text { Bias }\end{array}$ & $\begin{array}{l}\text { Mean } \\
\text { difference/ } \\
\text { ratio }\end{array}$ & $P$ value \\
\hline & $K_{\mathrm{e}}$ using C-G CrCl-IBW $\left(\mathrm{h}^{-1}\right)$ & 0.0557 & 0.0511 & 0.0046 & 0.474 \\
& $K_{\mathrm{e}}$ using C-G CrCl-ABW $\left(\mathrm{h}^{-1}\right)$ & 0.0693 & & 0.0182 & 0.012 \\
& $K_{\mathrm{e}}$ using C-G CrCl-AdjBW $\left(\mathrm{h}^{-1}\right)$ & 0.0611 & & 0.0100 & 0.120 \\
& $K_{\mathrm{e}}$ using S-C CrCl-ABW $\left(\mathrm{h}^{-1}\right)$ & 0.0671 & & 0.0160 & 0.019 \\
\multirow{3}{*}{ Precision } & $K_{\mathrm{e}}$ using C-G CrCl-IBW $\left(\mathrm{h}^{-1}\right)$ & 0.0387 & 0.0494 & 1.629 & 0.195 \\
& $\mathrm{~K}_{\mathrm{e}}$ using C-G CrCl-ABW $\left(\mathrm{h}^{-1}\right)$ & 0.0480 & & 1.059 & 0.877 \\
& $K_{\mathrm{e}}$ using C-G CrCl-AdjBW $\left(\mathrm{h}^{-1}\right)$ & 0.0416 & & 1.410 & 0.358 \\
& $K_{\mathrm{e}}$ using S-C CrCl-ABW $\left(\mathrm{h}^{-1}\right)$ & 0.0456 & & 1.174 & 0.673 \\
\hline
\end{tabular}

$A B W$ actual body weight, $A d j B W$ adjusted body weight, $C G$ Cockcroft-Gault, $C r C l$ creatinine clearance, $I B W$ ideal body weight, $S-C$ Salazar-Corcoran

\begin{tabular}{llllrr}
\hline Outcome & Predictor variables & $\begin{array}{l}\text { Population- } \\
\text { predicted } t_{1 / 2}\end{array}$ & $\begin{array}{l}\text { Patient- } \\
\text { specific } t_{1 / 2}\end{array}$ & $\begin{array}{l}\text { Mean differ- } \\
\text { ence/ratio }\end{array}$ & $P$ value \\
\hline Bias & $t_{1 / 2}$ using C-G CrCl-IBW (h) & 19.38 & 27.71 & -8.33 & 0.003 \\
& $t_{1 / 2}$ using C-G CrCl-ABW (h) & 16.31 & & -11.41 & $<0.001$ \\
& $t_{1 / 2}$ using C-G CrCl-AdjBW (h) & 17.83 & & -9.89 & 0.001 \\
& $t_{1 / 2}$ using S-C CrCl-ABW (h) & 16.26 & & -11.45 & $<0.001$ \\
Precision & $t_{1 / 2}$ using C-G CrCl-IBW (h) & 13.20 & 21.60 & 2.68 & 0.010 \\
& $t_{1 / 2}$ using C-G CrCl-ABW (h) & 12.57 & & 2.95 & 0.005 \\
& $t_{1 / 2}$ using C-G CrCl-AdjBW (h) & 12.69 & & 2.90 & $<0.001$ \\
& $t_{1 / 2}$ using S-C CrCl-ABW (h) & 11.59 & & 3.47 & 0.001 \\
\hline
\end{tabular}

$A B W$ actual body weight, $A d j B W$ adjusted body weight, $C G$ Cockcroft-Gault, $C r C l$ creatinine clearance, $I B W$ ideal body weight, $S-C$ Salazar-Corcoran
Table 7 Mean bias and precision difference between population-predicted half-life $\left(t_{1 / 2}\right)$ and patient-specific $\mathrm{t}_{1 / 2}$ in all patients $(n=30)$
Table 9 Relationship between population-predicted half-life $\left(t_{1 / 2}\right)$ and patient-specific $\mathrm{t}_{1 / 2}$ in obese patients $(n=10)$ constant $\left(K_{\mathrm{e}}\right)$ and patient-specific $K_{\mathrm{e}}$ in obese patients $(n=10)$

\begin{tabular}{llll}
\hline Predictor variables & \multicolumn{3}{l}{$\begin{array}{l}\text { Patient-specific } K_{\mathrm{e}} \text { outcome } \\
\text { variable }\end{array}$} \\
\cline { 2 - 4 } & $r$ & $\beta \pm \mathrm{SE}$ & $P$ value \\
\hline$K_{\mathrm{e}}$ using C-G CrCl-IBW $\left(\mathrm{h}^{-1}\right)$ & 0.772 & $0.962 \pm 0.280$ & 0.009 \\
$K_{\mathrm{e}}$ using C-G CrCl-ABW $\left(\mathrm{h}^{-1}\right)$ & 0.752 & $0.624 \pm 0.193$ & 0.012 \\
$K_{\mathrm{e}}$ using C-G CrCl-AdjBW $\left(\mathrm{h}^{-1}\right)$ & 0.766 & $0.800 \pm 0.237$ & 0.010 \\
$K_{\mathrm{e}}$ using S-C CrCl-ABW $\left(\mathrm{h}^{-1}\right)$ & 0.754 & $0.717 \pm 0.221$ & 0.012 \\
\hline
\end{tabular}

$A B W$ actual body weight, $A d j B W$ adjusted body weight, $C G$ Cockcroft-Gault, $\mathrm{CrCl}$ creatinine clearance, $\mathrm{IBW}$ ideal body weight, $S-C$ Salazar-Corcoran, SE standard error

frequency. The equations used in this study for measuring $\mathrm{CrCl}$ provide $\mathrm{CrCl}$ estimates compared to 24-h urine collection and these equations do not account for rapid changes in $\mathrm{CrCl}$ among patients with renal dysfunction. Additionally, we acknowledge that not assessing the area under the curve to

\begin{tabular}{llll}
\hline Predictor variables & \multicolumn{3}{l}{$\begin{array}{l}\text { Patient-specific } \mathrm{t}_{1 / 2} \text { outcome } \\
\text { variable }\end{array}$} \\
\cline { 2 - 4 } & $r$ & $\beta \pm \mathrm{SE}$ & $P$ value \\
\hline$t_{1 / 2}$ using C-G CrCl-IBW (h) & 0.657 & $0.839 \pm 0.340$ & 0.039 \\
$t_{1 / 2}$ using C-G CrCl-ABW (h) & 0.602 & $1.176 \pm 0.551$ & 0.066 \\
$t_{1 / 2}$ using C-G CrCl-AdjBW (h) & 0.637 & $0.998 \pm 0.427$ & 0.048 \\
$t_{1 / 2}$ using S-C CrCl-ABW (h) & 0.640 & $1.052 \pm 0.446$ & 0.046 \\
\hline
\end{tabular}

$A B W$ actual body weight, $A d j B W$ adjusted body weight, $C G$ Cockcroft-Gault, $\mathrm{CrCl}$ creatinine clearance, $I B W$ ideal body weight, $S-C$ Salazar-Corcoran, SE standard error

minimum inhibitory concentration is a limitation of our study as emerging evidence is pointing to this measure as a better pharmacokinetic/pharmacodynamic marker for monitoring vancomycin efficacy while ensuring patient safety and guiding vancomycin dose optimization [25-29]. 
Table 10 Relationship between population-predicted elimination rate constant $\left(K_{\mathrm{e}}\right)$ and patient-specific $K_{\mathrm{e}}$ in patients with renal dysfunction $(n=17)$

\begin{tabular}{llrr}
\hline Predictor variables & \multicolumn{3}{l}{$\begin{array}{l}\text { Patient-specific } K_{\mathrm{e}} \text { outcome } \\
\text { variable }\end{array}$} \\
\cline { 2 - 4 } & \multicolumn{4}{l}{$\beta \pm \mathrm{SE}$} & $P$ value \\
\hline$K_{\mathrm{e}}$ using C-G CrCl-IBW $\left(\mathrm{h}^{-1}\right)$ & 0.691 & $0.680 \pm 0.184$ & 0.002 \\
$K_{\mathrm{e}}$ using C-G CrCl-ABW $\left(\mathrm{h}^{-1}\right)$ & 0.785 & $0.545 \pm 0.111$ & $<0.001$ \\
$K_{\mathrm{e}}$ using C-G CrCl-AdjBW $\left(\mathrm{h}^{-1}\right)$ & 0.749 & $0.643 \pm 0.147$ & 0.001 \\
$K_{\mathrm{e}}$ using S-C CrCl-ABW $\left(\mathrm{h}^{-1}\right)$ & 0.744 & $0.587 \pm 0.136$ & 0.001 \\
\hline
\end{tabular}

$A B W$ actual body weight, $A d j B W$ adjusted body weight, $C G$ Cockcroft-Gault, $\mathrm{CrCl}$ creatinine clearance, $I B W$ ideal body weight, $S-C$ Salazar-Corcoran, $S E$ standard error

Table 11 Relationship between population-predicted half-life $\left(t_{1 / 2}\right)$ and patient-specific $t_{1 / 2}$ in patients with renal dysfunction $(n=17)$

\begin{tabular}{llll}
\hline Predictor variables & \multicolumn{3}{l}{$\begin{array}{l}\text { Patient-specific } t_{1 / 2} \text { outcome } \\
\text { variable }\end{array}$} \\
\cline { 2 - 4 } & $r$ & $\beta \pm \mathrm{SE}$ & $P$ value \\
\hline$t_{1 / 2}$ using C-G CrCl-IBW (h) & 0.593 & $0.988 \pm 0.347$ & 0.012 \\
$t_{1 / 2}$ using C-G CrCl-ABW (h) & 0.604 & $0.995 \pm 0.340$ & 0.010 \\
$t_{1 / 2}$ using C-G CrCl-AdjBW (h) & 0.615 & $1.048 \pm 0.347$ & 0.009 \\
$t_{1 / 2}$ using S-C CrCl-ABW (h) & 0.591 & $1.108 \pm 0.390$ & 0.012 \\
\hline
\end{tabular}

$A B W$ actual body weight, $A d j B W$ adjusted body weight, $C G$ Cockcroft-Gault, $\mathrm{CrCl}$ creatinine clearance, $I B W$ ideal body weight, $S-C$ Salazar-Corcoran, $S E$ standard error

\section{Conclusions}

The study found that regardless of the $\mathrm{CrCl}$ estimation method used, population-predicted $\mathrm{K}_{\mathrm{e}}$ was significantly correlated with patient-specific $K_{\mathrm{e}}$. Population-predicted $K_{\mathrm{e}}$ using $\mathrm{C}-\mathrm{G} \mathrm{CrCl}-\mathrm{AdjBW}$ had the strongest correlation with patient-specific $K_{\mathrm{e}}$ in all patients. Among special populations assessed, population-predicted $K_{\mathrm{e}}$ using $\mathrm{C}-\mathrm{G} \mathrm{CrCl}-$ IBW had the strongest correlation with patient-specific $K_{\mathrm{e}}$ in obese patients and population-predicted $K_{\mathrm{e}}$ using C-G $\mathrm{CrCl}-\mathrm{ABW}$ had the strongest correlation in patients with renal dysfunction. The vancomycin population-predicted pharmacokinetic formula can be used safely to estimate a patient's vancomycin pharmacokinetics in hospitalized adult patients.

\section{Compliance with Ethical Standards}

Funding No external source of funding was used to assist with the preparation of this article.

Conflict of interest IfeanyiChukwu O. Onor, Alison Neuliep, Kieu Anh Tran, Jennifer Lambert, Christopher J. Gillard, Fatima Brakta,
Michael C. Ezebuenyi, Kirbie St. James, John I. Okogbaa, and Robbie A. Beyl have no conflicts of interest that are relevant to the content of this article.

Ethics Approval The Institutional Review Board of the Xavier University of Louisiana and the University Medical Center Research Review Committee reviewed and approved this study protocol in accordance with the ethical standards set forth in the 1964 Declaration of Helsinki.

Open Access This article is licensed under a Creative Commons Attribution-NonCommercial 4.0 International License, which permits any non-commercial use, sharing, adaptation, distribution and reproduction in any medium or format, as long as you give appropriate credit to the original author(s) and the source, provide a link to the Creative Commons licence, and indicate if changes were made. The images or other third party material in this article are included in the article's Creative Commons licence, unless indicated otherwise in a credit line to the material. If material is not included in the article's Creative Commons licence and your intended use is not permitted by statutory regulation or exceeds the permitted use, you will need to obtain permission directly from the copyright holder.To view a copy of this licence, visit http://creativecommons.org/licenses/by-nc/4.0/.

\section{References}

1. Rybak M, Lomaestro B, Rotschafer JC, et al. Therapeutic monitoring of vancomycin in adult patients: a consensus review of the American Society of Health-System Pharmacists, the Infectious Diseases Society of America, and the Society of Infectious Diseases Pharmacists. Am J Health Syst Pharm. 2009;66(1):82-98. https://doi.org/10.2146/ajhp080434.

2. Matzke GR, McGory RW, Halstenson CE, Keane WF. Pharmacokinetics of vancomycin in patients with various degrees of renal function. Antimicrob Agents Chemother. 1984;25(4):433-7. https ://doi.org/10.1128/AAC.25.4.433.

3. Oswalt A, Joseph AC, Sima A, Kurczewski L. Evaluation of intravenous vancomycin pharmacokinetic parameters in patients with acute brain injury. J Pharm Pract. 2017;32(2):132-8. https://doi. org/10.1177/0897190017743133.

4. Murphy JE, Gillespie DE, Bateman CV. Predictability of vancomycin trough concentrations using seven approaches for estimating pharmacokinetic parameters. Am J Health Syst Pharm. 2006;63(23):2365-70. https://doi.org/10.2146/ajhp060047.

5. Leader WG, Chandler MHH, Castiglia M. Pharmacokinetic optimisation of vancomycin therapy. Clin Pharmacokinet. 1995;28(4):327-42. https://doi.org/10.2165/00003088-19952 8040-00005.

6. Colin PJ, Allegaert K, Thomson AH, et al. Vancomycin pharmacokinetics throughout life: results from a pooled population analysis and evaluation of current dosing recommendations. Clin Pharmacokinet. 2019;58(6):767-80. https://doi.org/10.1007/ s40262-018-0727-5.

7. Yamamoto M, Kuzuya T, Baba H, Yamada K, Nabeshima T. Population pharmacokinetic analysis of vancomycin in patients with gram-positive infections and the influence of infectious disease type. J Clin Pharm Ther. 2009;34(4):473-83. https://doi.org/10.1 111/j.1365-2710.2008.01016.x.

8. Li X, Sun S, Ling X, Chen K, Wang Q, Zhao Z. Plasma and cerebrospinal fluid population pharmacokinetics of vancomycin in postoperative neurosurgical patients after combined intravenous and intraventricular administration. Eur J Clin 
Pharmacol. 2017;73(12):1599-607. https://doi.org/10.1007/s0022 8-017-2313-4.

9. Revilla N, Martín-Suárez A, Pérez MP, González FM, De Gatta FMDM. Vancomycin dosing assessment in intensive care unit patients based on a population pharmacokinetic/pharmacodynamic simulation. Br J Clin Pharmacol. 2010;70(2):201-12. https ://doi.org/10.1111/j.1365-2125.2010.03679.x.

10. Salazar DE, Corcoran GB. Predicting creatinine clearance and renal drug clearance in obese patients from estimated fatfree body mass. Am J Med. 1988;84(6):1053-60. https://doi. org/10.1016/0002-9343(88)90310-5.

11. Spinler SA, Nawarskas JJ, Boyce EG, Connors JE, Charland SL, Goldfarb S. Predictive performance of ten equations for estimating creatinine clearance in cardiac patients. Iohexol Cooperative Study Group. Ann Pharmacother. 1998;32(12):1275-83.

12. Cockcroft, Donald W, Gault MH. Prediction of creatinine clearance from serum creatinine. Nephron. 1976;16(1):31-41.

13. Pai MP, Paloucek FP. The origin of the "ideal" body weight equations. Ann Pharmacother. 2000;34(9):1066-9. https://doi. org/10.1345/aph.19381.

14. Demirovic JA, Pai AB, Pai MP. Estimation of creatinine clearance in morbidly obese patients. Am J Health Syst Pharm. 2009;66(7):642-8. https://doi.org/10.2146/ajhp080200.

15. Winter MA, Guhr KN, Berg GM. Impact of various body weights and serum creatinine concentrations on the bias and accuracy of the Cockcroft-Gault equation. Pharmacotherapy. 2012;32(7):60412. https://doi.org/10.1002/j.1875-9114.2012.01098.x.

16. Kidney Disease: Improving Global Outcomes (KDIGO) Acute Kidney Injury Work Group. KDIGO clinical practice guideline for acute kidney injury. Kidney Int Suppl. 2012;2:1-138. https:// doi.org/10.1038/kisup.2012.3.

17. Kidney Disease: Improving Global Outcomes (KDIGO) CKD Work Group. KDIGO 2012 clinical practice guideline for the evaluation and management of chronic kidney disease. Kidney Int Suppl. 2013;3(1):1-150. https://doi.org/10.1038/kisup.2012.76.

18. U.S. Centers for Medicare \& Medicaid Services. End-stage renal disease (ESRD). 2013. https://www.cms.gov/Medicare/Coord ination-of-Benefits-and-Recovery/Coordination-of-Benefitsand-Recovery-Overview/End-Stage-Renal-Disease-ESRD/ESRD. html. Accessed 1 May 2019.

19. Riccobono DE, Monteagudo-Chu MO. Vancomycin. In: Cohen H, editor. Casebook in clinical pharmacokinetics and drug dosing. New York (NY): McGraw-Hill Education; 2015. http://accessphar macy. mhmedical.com/content.aspx?aid $=1112259650$. Accessed 4 Mar 2020.
20. Bauer LA. Vancomycin. In: Applied clinical pharmacokinetics. 3rd ed. New York (NY): McGraw-Hill Medical; 2015. http:// accesspharmacy.mhmedical.com/content.aspx?aid=1106303111. Accessed 4 Mar 2020.

21. University Medical Center New Orleans. Vancomycin dosing guide. New Orleans, LA: University Medical Center New Orleans; 2018.

22. Dionne RE, Bauer LA, Gibson GA, Griffen WO, Blouin RA. Estimating creatinine clearance in morbidity obese patients. Am J Hosp Pharm. 1981;38(6):841-4.

23. Jelliffe RW, Jelliffe SM. A computer program for estimation of creatinine clearance from unstable serum creatinine levels, age, sex, and weight. Math Biosci. 1972;14(1-2):17-24. https://doi. org/10.1016/0025-5564(72)90003-X.

24. Chiou WL, Hsu FH. A new simple and rapid method to monitor the renal function based on pharmacokinetic consideration of endogeneous creatinine. Res Commun Chem Pathol Pharmacol. 1975;10(2):315-30.

25. Rybak M, Le J, Lodise T, et al. Therapeutic monitoring of vancomycin: a revised consensus guideline and review of the American Society of Health-System Pharmacists, the Infectious Diseases Society of America, the Pediatric Infectious Diseases Society and the Society of Infectious Diseases Pharmacists. 2018. Available from: https://www.ashp.org/-/media/assets/policy-guidelines /docs/draft-guidelines/draft-guidelines-ASHP-IDSA-PIDS-SIDPtherapeutic-vancomycin.ashx. Accessed 4 Mar 2020.

26. Heil EL, Claeys KC, Mynatt RP, et al. Making the change to area under the curve-based vancomycin dosing. Am J Health Syst Pharm. 2018;75(24):1986-95. https://doi.org/10.2146/ajhp180034.

27. Lodise TP, Rosenkranz SL, Finnemeyer M, et al. The emperor's new clothes: prospective observational evaluation of the association between initial vancomycin exposure and failure rates among adult hospitalized patients with MRSA bloodstream infections (PROVIDE). Clin Infect Dis. 2019. https://doi.org/10.1093/cid/ ciz460 (Epub ahead of print).

28. Suzuki Y, Kawasaki K, Sato Y, et al. Is peak concentration needed in therapeutic drug monitoring of vancomycin? A pharmacokinetic-pharmacodynamic analysis in patients with methicillinresistant Staphylococcus aureus pneumonia. Chemotherapy. 2012;58(4):308-12. https://doi.org/10.1159/000343162.

29. Lodise TP, Patel N, Lomaestro BM, Rodvold KA, Drusano GL. Relationship between initial vancomycin concentration-time profile and nephrotoxicity among hospitalized patients. Clin Infect Dis. 2009;49(4):507-14. https://doi.org/10.1086/600884.

\section{Affiliations}

\section{IfeanyiChukwu O. Onor ${ }^{1,2,3}$. Alison Neuliep ${ }^{1,3} \cdot$ Kieu Anh Tran ${ }^{1}$. Jennifer Lambert ${ }^{3}$. Christopher J. Gillard ${ }^{1,2,3}$. Fatima Brakta $^{2,3} \cdot$ Michael C. Ezebuenyi $^{4} \cdot$ Kirbie St. James $^{3} \cdot$ John I. Okogbaa ${ }^{1,2} \cdot$ Robbie A. Beyl $^{5}$}

\section{IfeanyiChukwu O. Onor \\ ionor@xula.edu}

1 College of Pharmacy, Xavier University of Louisiana, 1 Drexel Drive, Box COP, New Orleans, LA 70125, USA

2 Department of Medicine, Louisiana State University Health Sciences Center School of Medicine, 1542 Tulane Avenue, New Orleans, LA 70112, USA
3 Department of Pharmacy, University Medical Center New Orleans, 2000 Canal Street, New Orleans, LA 70112, USA

4 Department of Pharmacy, Our Lady of the Lake Regional Medical Center, 5000 Hennessy Boulevard, Baton Rouge, LA 70808, USA

5 Pennington Biomedical Research Center, 6400 Perkins Road, Baton Rouge, LA 70808, USA 